\title{
Analisis Potensi Pajak Daerah Sebagai Sumber Pendapatan Asli Daerah di Kabupaten Tanjung Jabung Barat
}

\author{
Pantun Bukit ${ }^{1}$, Hana Tamara Putri ${ }^{2}$ \\ Fakultas Ekonomi Universitas Batanghari Jambi ${ }^{1,2}$
}

\begin{abstract}
Tax areas as one of the components of the Original Local Revenue (PAD) which is given by the local Government to residents who stay in their jurisdiction without obtaining the consideration from the local governments that collect taxes area. Tanjung Jabung Barat District is one of the strategic areas and it has a potential of natural resources which is relatively large. The strategies and policies of financial development in Tanjung Jabung Barat is directed at the improvement of the effectiveness as well as the effectiveness of regional finance. One of the strategies is through the optimization of local tax receipts as a source of Original Local Revenue (PAD). This research aimed at investigating the magnitude of the potential and the local tax capacity in Tanjung Jabung Barat District of 2018. This research also intended to know the implementation of tax effort which has been attempted in Tanjung Jabung Barat District. Last, this research aimed at knowing the extent to which the original revenue dependency area toward the acceptance of tax areas in Tanjung Jabung Barat District.The data were collected through survey and direct observation to the research subject through the coordination with related agencies. In data analysis method, Diagrams Cartesius, Regression approach to Tax Business, Estimation and Elasticity Tax Formulas, analysis of Overlay and analysis of Potential local tax were used. The results of this research are expected to give input to the Government of Tanjung Jabung Barat in arranging the strategies and policies in optimizing the Local Tax Revenue.
\end{abstract}

Key Words: Local Tax, Original Local Revenue, Optimization of Taxes.

\section{PENDAHULUAN}

Pajak daerah sebagai salah satu komponen Pendapatan Asli Daerah (PAD) adalah merupakan pajak yang dikenakan pemerintah daerah kepada penduduk yang mendiami wilayah yurisdiksinya tanpa langsung memperoleh kontraprestasi yang diberikan oleh pemerintah daerah yang memungut pajak daerah yang dibayarkannya. Agar pemerintah daerah memiliki kemampuan optimal untuk memungut pajak daerah yang ada didaerahnya perlu kiranya mempertimbangkan pajak-pajak daerah yang memang sesuai untuk dijadikan sumber pendapatan agar tercipta efisiensi dan efektivitas dalam penerimaan pajak daerah.

Kabupaten Tanjung Jabung Barat merupakan salah satu daerah yang sangat strategis dan memiliki potensi sumberdaya alam relatif besar. Strategi dan kebijakan pembangunan bidang keuangan Kabupaten Tanjung Jabung Barat diarahkan pada peningkatan efektivitas dan peningkatan daya guna keuangan daerah Tanjung Jabung Barat melalui restrukturisasi peraturan daerah, peningkatan kualitas pelayanan kepada masyarakat wajib pajak dan retribusi, dan optimalisasi kinerja Organisasi Perangkat Daerah Penghasil, serta peningkatan pendayagunaan aset-aset daerah dan BUMD.
Oleh karena itu, diupayakan penggalangan sumber-sumber Pendapatan Asli Daerah serta sumber-sumber pendapatan lainnya yang sah. Penyertaan modal kepada badan usaha milik daerah (BUMD) dilakukan dengan mengembangkan opsi kolateral dan pembelian saham BUMD yang maju.

Tujuan dari analisis dan pembahasan dalam penelitian ini adalah: 1) Mengetahui dan mengidentifikasi besarnya potensi dan kapasitas pajak daerah (tax capacity) di Kabupaten Tanjung Jabung Barat, sehingga dari potensi tersebut dapat menjadi landasan untuk mencari solusi dalam merealisasikan potensi pajak daerah di Kabupaten Tanjung Jabung Barat Tahun 2018; 2) Mengetahui dan mengevaluasi sejauh mana usaha pajak (tax effort) yang telah diupayakan selama ini di Kabupaten Tanjung Jabung Barat; 3) Merumuskan strategi kebijakan dalam mengoptimalisasikan penerimaan pajak daerah di di Kabupaten Tanjung Jabung Barat; dan 4) Mengetahui dan menganalisis pengaruh penerimaan Pajak Daerah terhadap Pendapatan Asli Daerah dengan pendekatan model regeresi multivariat

\section{METODE PENELITIAN}

Jenis dan Sumber Data

Dalam penelitian ini menggunakan dua 
jenis data yaitu Data Primer adalah Data yang diperoleh langsung dari responden,yaitu para pelaku usaha dan kepala OPD yang ada di lingkup Pemerintah Kabupaten Tanjung Jabung Barat yang terkait dengan pajak daerah, data ini diperoleh dengan tanya jawab kepada responden secara langsung. Hasil dari kuesioner tersebut merupakan data yang digunakan untuk melihat sejauhmana potensi pajak daerah di Kabupaten Tanjung Jabung Barat.

Data sekunder yang diperoleh dalam penyusunan laporan Kajian Potensi Pajak Daerah Kabupaten Tanjung Jabung Barat ini sebagian besar diperoleh dari data lapangan yang bersumber dari unit kerja terkait/instansi atau organisasi perangkat daerah (OPD) pengelola pajak daerah dan laporan tahunan Badan Pengelola Pajak dan Retribusi Daerah Kabupaten Tanjung Jabung Barat serta laporan Perhitungan APBD Kabupaten Tanjung Jabung Barat.

\section{Metode Pengumpulan Data}

Metode Pengumpulan Data dilakukan melalui survey dan observasi langsung terhadap subjek penelitian dan melalui koordinasi dengan instansi yang terkait serta studi referensi dari sumber data pendukung.

\section{Objek Penelitian}

Adapun yang menjadi Objek pada Penelitian ini adalah Kabupaten Tanjung Jabung Barat..

\section{Teknik Pengumpulan data}

Adapun teknik pengumpulan data yang digunakan adalah :

1. Studi literatur, yaitu dengan melakukan kajian yang terkait dengan objek pajak daerah dan pendapatan asli daerah.

2. Wawancara, yaitu tekhnik pengumpulan data dengan melakukan tanya jawab secara lisan dengan orang-orang yang dinilai berwenang dalam pengelolaan dan pemungutan pajak daerah seperti kepala Organisasi Perangkat Daerah (OPD) dan kepala bidang pemungutan dan penetapan pajak daerah.

\section{Metode Analisis Data \\ Diagram Cartesius}

Untuk mengetahui seberapa jauh pemerintah Kabupaten Tanjung Jabung Barat telah melakukan optimalisasi penerimaan pajak daerah, maka dilakukan analisis terhadap kapasitas pajak (tax capacity), usaha pajak (tax effort) dan pertumbuhan pajak (tax growth). Kondisi optimal dari penerimaan pemerintah adalah kondisi penerimaan dengan high capacity- high effort dan high capacity- high growth yang akan memperkuat aspek fundamental.

\section{Pendekatan Regresi terhadap Analisis Tax Effort dan Tax Ratio}

Usaha-usaha telah dilakukan untuk menerangkan secara statistika berbagai variasi dalam rasio pajak, karena manfaat potensialnya untuk perbandingan antar negara yang berarti dalam besarnya sektor publik. Yang dimaksud dengan rasio pajak disini adalah rasio antara besarnya pajak yang diterima pemerintah dengan Produk Domestik Regional Bruto. Analisisanalisis ini biasanya menggunakan model persamaan tunggal untuk mengidentifikasi determinan-determinan dari perbedaan antar negara dan antar daerah dalam rasio pajak.

\section{Pendekatan Dengan Usaha Pajak (Tax Effort).}

Usaha pajak adalah rasio antara pajak yang secara aktual dapat dipungut dengan kapasitas pajak. Dalam rangka memberikan urutan negara-negara berdasarkan usaha pajak, rasio pajak diasumsikan sebagai fungsi dari dua faktor umum : kapasitas pajak ( $T / Y)$; dan usaha pajak $(E)$, sebagai berikut :

$$
T / Y=f(T / Y, E)
$$

Karena T/Y adalah kapasitas pajak dan usaha pajak didefenisikan dengan sejauh mana kapasitas pajak dimanfaatkan, rasio usaha pajak dalam negara manapun dapat diperoleh sebagai berikut :

$$
\text { Atau } \begin{aligned}
E & =(T / Y) /(T / Y) \\
E_{i} & =T_{i} / T_{i}
\end{aligned}
$$

Jadi rasio usaha untuk negara ke-i adalah rasio dari pajak aktual yang dapat dipungut terhadap pajak yang diharapkan dapat dipungut.

\section{Analisis Klasifikasi Jenis Pajak Daerah (Overlay)}

Analisis Overlay dimaksud adalah untuk melihat deskripsi kegiatan jenis pajak daerah yang potensial berdasarkan kriteria pertumbuhan dan kriteria kontribusi. 


\section{Analisis Regresi}

Untuk menjawab tujuan yang keempat digunakan pendekatan alat statistik dengan analisis regresi berganda, dimana Pendapatan Asli Daerah sebagai Variabel Dependen dan Pajak Daerah sebagai Variabel Independen yang terdiri dari Pajak Hotel, Pajak Restoran, Pajak Hiburan, Pajak Reklame, Pajak Penerangan Jalan, Pajak Mineral Bukan Logam dan Batuan, Pajak Parkir, Pajak Air Tanah, Pajak Hasil Sarang Burung Walet, Pajak Bumi dan Bangunan Perdesaan dan Perkotaan dan Bea Perolehan Hak atas Tanah dan Bangunan (BPHTB). Adapun model atau persamaan yang dibangun adalah sebagai berikut:

Persamaan regresi adalah sebagai berikut:

dimana :

$$
\mathbf{Y}=\mathbf{a}_{0}+\mathbf{a}_{\mathbf{i}} \mathbf{X}_{\mathbf{i}}+\mathbf{\varepsilon}
$$

$\mathrm{Y}=$ Pendapatan Asli Daerah (PAD)

$\mathrm{a}_{0}=$ Parameter (Konstanta)

$a_{i}=$ Koefeisien Regresi ke i, dimana i adalah pajak daerah $=1-10$

$\mathrm{Xi}=$ Pajak Daerah ( Hotel, Restoran, Hiburan, Reklame, Penerangan jalan, Mineral bukan logam dan batuan, air bawah tanah, sarang burung walet, PBB-P2 dan BPHTB)

\section{HASIL DAN PEMBAHASAN \\ Penerimaan Pajak Daerah}

Tabel 1. Perkembangan Pajak Daerah Kabupaten Tanjung Jabung Barat Tahun 2011-2016. (Rp Jutaan)

\begin{tabular}{rrrrrrrrrrrr}
\hline \multicolumn{7}{c}{ Tahun } & Hotel & Restoran Hiburan Reklame Penerangan Jln Mineral Air Bawah Tanah Sarang Burung Walet PBB P2 BPHTB & PD \\
\hline 2011 & 94,94 & 616,81 & 11,95 & 201,50 & $1.962,73$ & $1.510,72$ & 5,47 & 323,10 & 0,00 & $3.727,33$ & $8.454,55$ \\
2012 & 158,96 & $1.014,62$ & 3,60 & 287,20 & $3.187,08$ & $2.149,80$ & 7,92 & 237,52 & 0,00 & 939,86 & $7.986,56$ \\
2013 & 193,62 & $1.014,29$ & 81,48 & 253,77 & $8.794,92$ & $1.373,93$ & 18,81 & 133,96 & 0,00 & 240,82 & $12.105,60$ \\
2014 & 204,79 & $1.866,24$ & 13,30 & 272,28 & $8.504,01$ & 801,00 & 17,11 & 98,25 & $4.372,36$ & $4.556,28$ & $20.705,61$ \\
2015 & 110,67 & $2.033,10$ & 3,39 & 298,98 & $9.813,13$ & 400,86 & 16,90 & 140,50 & $4.635,48$ & $2.199,83$ & $19.652,84$ \\
2016 & 163,42 & $2.278,66$ & 3,13 & 351,32 & $11.580,12$ & $1.069,35$ & 25,15 & 277,30 & $4.521,88$ & $7.200,74$ & $27.471,08$ \\
GR (\%) & 11,47 & 29,87 & $-23,51$ & 11,76 & 42,62 & $-6,68$ & 35,69 & $-3,01$ & 1,70 & 14,08 & 26,58 \\
\hline
\end{tabular}

Sumber : $\quad$ 1. BPPRD Kabupaten Tanjung Jabung Barat 2011-2016

2. Bappeda dan LKPJ Bupati Tanjung Jabung Barat 2011-2016

Ket. GR $(\%) \quad=$ Pertumbuhan rata-rata dalam persentase

$\mathrm{PD} \quad=$ Pajak Daerah

Tabel 2. Pertumbuhan Masing-masing Pajak Daerah Kabupaten Tanjung Jabung Barat Tahun 2011-2016 (\%)

\begin{tabular}{|c|c|c|c|c|c|c|c|c|c|c|}
\hline Tahun & Hotel & Restoran & Hiburan & Reklame & Penerangan Jalan & Mineral & Air Bawah Tanah & Sarang Burung Walet & PBB P2 & BPHTB PD \\
\hline \multicolumn{11}{|l|}{2011} \\
\hline 2012 & 67,43 & 64,49 & $-69,86$ & 42,53 & 62,38 & 42,30 & 44,94 & $-26,49$ & 0,00 & $\begin{array}{lll}-74,78 & -5,54\end{array}$ \\
\hline 2013 & 21,80 & $-0,03$ & 2161,37 & $-11,64$ & 175,96 & $-36,09$ & 137,49 & $-43,60$ & 0,00 & $-74,38 \quad 51,57$ \\
\hline 2014 & 5,77 & 83,99 & $-83,68$ & 7,29 & $-3,31$ & $-41,70$ & $-9,04$ & $-26,66$ & 0,00 & $1791,9771,04$ \\
\hline 2015 & $-45,96$ & 8,94 & $-74,50$ & 9,81 & 15,39 & $-49,95$ & $-1,27$ & 43,00 & 6,02 & $\begin{array}{lll}2 & -51,72 & -5,08\end{array}$ \\
\hline 2016 & 47,66 & 12,08 & $-7,66$ & 17,50 & 18,01 & 166,76 & 48,84 & 97,38 & $-2,45$ & $227,33 \quad 39,78$ \\
\hline Rata (\%) & 16,12 & 28,25 & 320,94 & 10,92 & 44,74 & 13,55 & 36,82 & 7,27 & 0,59 & $303,0725,30$ \\
\hline
\end{tabular}

Sumber: $\quad$ 1. BPPRD Kabupaten Tanjung Jabung Barat 2011-2016

2. Bappeda dan LKPJ Bupati Tanjung Jabung Barat 2011-2016

Ket. GR $(\%) \quad=$ Pertumbuhan rata-rata dalam persentase

PD $\quad=$ Pajak Daerah 
Tabel 3. Kontribusi (Share) Masing-masing Pajak Daerah Terhadap Total Penerimaan Pajak Daerah Kabupaten Tanjung Jabung Barat Tahun 2011-2016 (\%)

\begin{tabular}{|c|c|c|c|c|c|c|c|c|c|c|c|}
\hline ahun & Hote & stora & $17 \mathbf{n}$ & dame & enerangan Jalan & Mineral & Air Bawah Tanah & Sarang Burung Walet & PBB $\mathrm{F}$ & उPHI & OTAL \\
\hline 2011 & 1,123 & 7,296 & 0,141 & 2,383 & 23,215 & 17,869 & 0,065 & 3,822 & 0,000 & 44,087 & 100,00 \\
\hline 2012 & 21,990 & 12,704 & 0,045 & 3,596 & 39,906 & 26,918 & 0,099 & 2,974 & 0,000 & 11,768 & 100,00 \\
\hline 2013 & 31,599 & 8,379 & 0,673 & 2,096 & 72,652 & 11,350 & 0,155 & 1,107 & 0,000 & 1,989 & 100,00 \\
\hline 201 & $+0,989$ & 9,013 & 0,064 & 1,315 & 41,071 & 3,869 & 0,083 & 0,475 & 21,117 & 22,005 & 100,00 \\
\hline 2015 & 0,563 & 10,345 & 0,017 & 1,521 & 49,932 & 2,040 & 0,086 & 0,715 & 23,587 & 11,193 & 100,00 \\
\hline 2016 & 60,595 & 8,295 & 0,011 & 1,279 & 42,154 & 3,893 & 0,092 & 1,009 & 16,461 & 26,212 & 100,00 \\
\hline $\operatorname{SR}(\%)$ & 1,143 & 9,339 & 0,159 & 2,032 & 44,822 & 10,989 & 0,097 & 1,683 & 10,194 & 19,542 & 100,00 \\
\hline
\end{tabular}

Sumber: $\quad$ 1. BPPRD Kabupaten Tanjung Jabung Barat 2011-2016

2. Bappeda dan LKPJ Bupati Tanjung Jabung Barat 2011-2016

Ket. SR $(\%) \quad=$ Kontribusi (Share) rata-rata dalam persentase $\mathrm{PD} \quad=$ Pajak Daerah

Tabel 4. Kontribusi (Share) Masing-masing Pajak Daerah Terhadap Total Pendapatan Asli Daerah Kabupaten Tanjung Jabung Barat Tahun 2011-2016 (\%)

\begin{tabular}{rrrlllllllll}
\hline Tahun & \multicolumn{1}{c}{ Hotel Restoran Hiburan Reklame Penerangan Jalan Mineral Air bawah Tanah Sarang Burung PBB P2 BPHTB Pajak Daerah } \\
\hline 2011 & 0,216 & 1,401 & 0,027 & 0,458 & 4,460 & 3,433 & 0,012 & 0,734 & 0,000 & 8,469 & 19,210 \\
2012 & 0,301 & 1,922 & 0,007 & 0,544 & 6,039 & 4,073 & 0,015 & 0,450 & 0,000 & 1,781 & 15,133 \\
2013 & 0,305 & 1,596 & 0,128 & 0,399 & 13,843 & 2,162 & 0,030 & 0,211 & 0,000 & 0,379 & 19,053 \\
2014 & 0,225 & 2,052 & 0,015 & 0,299 & 9,350 & 0,881 & 0,019 & 0,108 & 4,807 & 5,010 & 22,766 \\
2015 & 0,163 & 2,989 & 0,005 & 0,440 & 14,426 & 0,589 & 0,025 & 0,207 & 6,814 & 3,234 & 28,891 \\
2016 & 0,190 & 2,653 & 0,004 & 0,409 & 13,482 & 1,245 & 0,029 & 0,323 & 5,265 & 8,384 & 31,983 \\
SR (\%) & $\mathbf{0 , 2 3 3}$ & $\mathbf{2 , 1 0 2}$ & $\mathbf{0 , 0 3 1}$ & $\mathbf{0 , 4 2 5}$ & $\mathbf{1 0 , 2 6 7}$ & $\mathbf{2 , 0 6 4}$ & $\mathbf{0 , 0 2 2}$ & $\mathbf{0 , 3 3 9}$ & $\mathbf{2 , 8 1 4}$ & $\mathbf{4 , 5 4 3}$ & $\mathbf{2 2 , 8 3 9}$ \\
\hline
\end{tabular}

Sumber: $\quad$ 1. BPPRD Kabupaten Tanjung Jabung Barat 2011-2016

2. Bappeda dan LKPJ Bupati Tanjung Jabung Barat 2011-2016

Ket. SR (\%) = Kontribusi (Share) rata-rata dalam persentase

Analisis Klasifikasi Jenis Pajak Daerah (Overlay Analysis)

Tabel 5. Klasifikasi Jenis Pajak Daerah Kabupaten Tanjung Jabung Tahun 2011-2016 Berdasarkan Analisis Overlay.

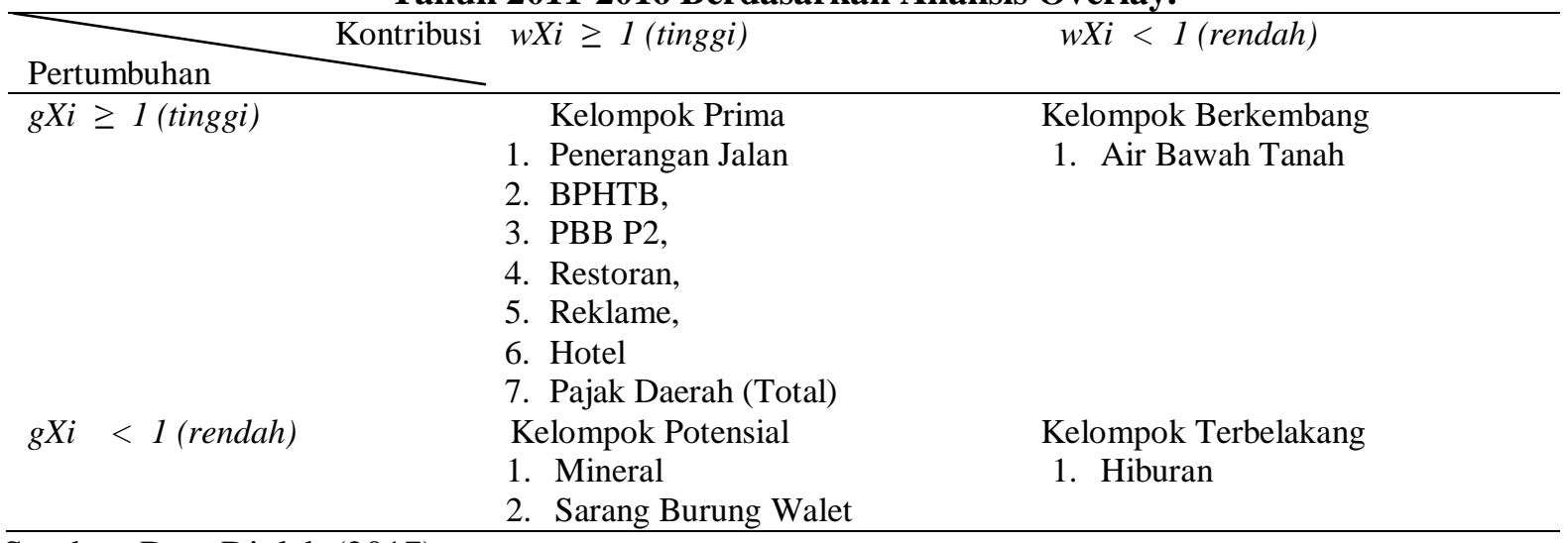

Sumber: Data Diolah (2017)

Keterangan : gXi adalah pertumbuhan setiap pajak daerah jenis i;

dan wXi adalah kontribusi setiap pajak daerah jenis i. 


\section{Rekapitulasi Rasio Pajak Daerah}

Tabel 6. Kapasitas Riil Pajak Daerah (T/Y) Pajak Daerah Kabupaten Tanjung Jabung Barat Tahun 2011-2016 (dalam persen)

\begin{tabular}{|c|c|c|c|c|c|c|c|c|c|c|c|}
\hline Tahun & Hotel & Restoran & Hiburan & Reklame F & Penerangan Jalan & Mineral & Air Bawah Tanah & Sarang Burung Walet & PBB P2 & BPHTB & Pajak Daerah \\
\hline 201 & 10,0008 & 0,0052 & 0,00010 & 0,0017 & 0,0165 & 0,0127 & 0,00005 & 0,0027 & 0,0000 & 0,0314 & 0,0713 \\
\hline 2012 & 20,0012 & 0,0078 & 0,00003 & 0,0022 & 0,0244 & 0,0165 & 0,00006 & 0,0018 & 0,0000 & 0,0072 & 0,0613 \\
\hline 201 & 30,0013 & 0,0067 & 0,00054 & 0,0017 & 0,0582 & 0,0091 & 0,00012 & 0,0009 & 0,0000 & 0,0016 & 0,0801 \\
\hline 201 & 40,0012 & 0,0111 & 0,00008 & 0,0016 & 0,0507 & 0,0048 & 0,00010 & 0,0006 & 0,0261 & 0,0272 & 0,1235 \\
\hline 201 & 50,0006 & 0,0107 & 0,00002 & 0,0016 & 0,0517 & 0,0021 & 0,00009 & 0,0007 & 0,0244 & 0,0116 & 0,1035 \\
\hline 201 & 60,0008 & 0,0108 & 0,00001 & 0,0017 & 0,0550 & 0,0051 & 0,00012 & 0,0013 & 0,0215 & 0,0342 & 0,1305 \\
\hline Rata $(\%$ & ) 0,0010 & 0,0087 & 0,0001 & 0,0017 & 0,0428 & 0,0084 & 0,0001 & 0,0013 & 0,0120 & 0,0189 & 0,0950 \\
\hline
\end{tabular}

Sumber: Analisis Data (2017)

\section{Potensi Pajak Daerah Kabupaten Tanjung Jabung Barat Tahun 2011-2016}

Pada pengujian secara parsial atau uji t, PDRB berpengaruh terhadap penerimaan pajak, dimana t hitung sebesar 6,597 $>\mathrm{t}$ tabel $=4,03$. Pada pengujian secara simultan melalui Uji F, Untuk $n=$ 6 dan degree of freedom (d.f) $=1$ dan 5 pada tingkat kesignifikanan 0.05 menurut tabel nilai-F kritis adalah 6,61, sedangkan pada tingkat 0,01 adalah 16,26 maka $F_{\text {hitung }}>F_{\text {tabel }}$ pada $\alpha=0.05$ dan pada $\alpha=0.01$. dengan demikian pengujian secara menyeluruh adalah signifikaan, yang menunjukkan bahwa memang ada hubungan antara $\mathrm{Y}$ dan $\mathrm{T}$. Selanjutnya, ternyata koefisien determinan $\mathrm{R}^{2}=$ 0.916 jauh lebih baik, artinya pengaruhnya relatif besar, sehingga model ini dapat dilanjutkan. Dengan demikian bentuk persamaan regresi dengan variabel terikat Pajak (T) dan variabel bebas PDRB (Y) pada periode yang sama selanjutnya dipakai untuk menghitung taxable capacity dan tax effort dari masing-

Model Pajak Daerah dianalisis regresi terhadap variabel bebas PDRB (tanpa Migas), menunjukkan signifikansi $\mathrm{F}$ hitung $=43,518>\mathrm{F}$ tabel $=5,79$ pada $\alpha=0,05$ dengan $\mathrm{R}^{2}=0,918$. Model Pajak Hotel tidak signifikan dimana tax capacity rata-ratanya hanya sebesar 0,0001 dengan $\mathrm{R}^{2}=$ 0,380 . Pajak restoran dan rumah makan signifikan dimana $\mathrm{F}$ hitung $>\mathrm{F}$ tabel dengan $\mathrm{R}^{2}=0,901$ dan tax capacity rata-ratanya sebesar 0,0087 . Untuk analisis regresi Pajak Hiburan pengujian hipotesis secara statistika adalah signifikan, namun koefisien regresinya menunjukkan nilainya sangat kecil yaitu 0,000007216, dengan tax capacity juga sangat kecil yaitu 0,0001. Untuk variabel Pajak Reklame dan Pajak Penerangan Jalan diregres terhadap bebas PDRB (tanpa Migas), pengujian hipotesis secara statistika adalah signifikan dan menunjukkan adanya hubungan antara penerimaan Pajak Reklame dan Pajak Penerangan Jalan dengan perubahan PDRB (tanpa Migas). Selanjutnya untuk analisis Pajak Mineral tidak signifikan terhadap PDRB (tanpa Migas). Namun tax capacity-nya relatif baik yaitu sebesar 0,0091 dengan tax effort rata-rata yang terendah dari semua jenis pajak daerah di Kabupaten Tanjung Jabung Barat selama periode 2011-2016.

\section{Realisasi dan Kapasitas Potensi Pajak Daerah}

Kas Tas Tas

\begin{tabular}{|c|c|c|c|c|}
\hline Tahun & $\begin{array}{c}\text { Realisasi Pajak } \\
\text { Daerah (Rp) }\end{array}$ & $\begin{array}{l}\text { Rasio Pajak } \\
\text { (T/Y) \% }\end{array}$ & $\begin{array}{l}\text { Kapasitas Potensi } \\
\text { Pajak Daerah }\left(\mathrm{T}^{\wedge}\right)\end{array}$ & $\begin{array}{c}\text { Taxable } \\
\text { Capacity }\left(T^{\wedge} / Y\right)\end{array}$ \\
\hline 2011 & 8.454 .549 .481 & 0,071258 & 8.373 .049 .765 & 0,0706 \\
\hline 2012 & 7.986.557.463 & 0,061263 & 9.134 .258 .816 & 0,0701 \\
\hline 2013 & 12.105 .598 .178 & 0,080085 & 11.286 .533 .505 & 0,0747 \\
\hline 2014 & 20.705 .606 .741 & 0,123513 & 18.319 .978 .801 & 0,1093 \\
\hline 2015 & 19.652 .841 .252 & 0,103499 & 22.150 .197 .543 & 0,1167 \\
\hline 2016 & 27.471 .080 .669 & 0,130463 & 28.555 .650 .939 & 0,1356 \\
\hline GR (\%) & 26,58 & 12,86 & 27,81 & 13,96 \\
\hline
\end{tabular}

Sumber: $\quad$ 1. BPPRD Kabupaten Tanjung Jabung Barat 2011-2016

2. Bappeda dan LKPJ Bupati Tanjung Jabung Barat 2011-2016

Ket. GR (\%) = Pertumbuhan rata-rata dalam persentase Data diolah (2017) 


\section{Rekapitulasi Kapasitas Potensi Pajak Daerah}

Tabel 8. Kapasitas Potensi Pajak Daerah $\left(T^{\wedge} / Y\right)$ Berdasarkan Jenis Pajak di Kabupaten Tanjung Jabung Barat Periode Tahun 2011-2016 (dalam persen).

\begin{tabular}{|c|c|c|c|c|c|c|c|c|c|c|c|}
\hline Tahun & $\mathrm{T}^{\wedge} / \mathrm{Y}$ Hotel & $\begin{array}{c}\mathrm{T}^{\wedge} / \mathrm{Y} \\
\text { Restoran } \\
\end{array}$ & $\begin{array}{c}\mathrm{T}^{\wedge} / \mathrm{Y} \\
\text { Hiburan } \\
\end{array}$ & $\begin{array}{c}\mathrm{T}^{\wedge} / \mathrm{Y} \\
\text { Reklame } \\
\end{array}$ & $\begin{array}{c}\mathrm{T}^{\wedge} / \mathrm{Y} \text { Penerangan } \\
\text { Jalan } \\
\end{array}$ & $\begin{array}{c}\mathrm{T}^{\wedge} / \mathrm{Y} \\
\text { Mineral } \\
\end{array}$ & $\begin{array}{c}\mathrm{T}^{\wedge} / \mathrm{Y} \text { Air } \\
\text { Bawah Tanah } \\
\end{array}$ & $\begin{array}{l}\mathrm{T}^{\wedge} / \mathrm{Y} \\
\mathrm{SBW}\end{array}$ & $\begin{array}{c}\mathrm{T}^{\wedge} / \mathrm{Y} \\
\mathrm{PBB} \mathrm{P} 2 \\
\end{array}$ & $\begin{array}{c}\mathrm{T}^{\wedge} / \mathrm{Y} \\
\mathrm{BPHTB} \\
\end{array}$ & $\begin{array}{c}\mathrm{T}^{\wedge} / \text { Y Pajak } \\
\text { Daerah }\end{array}$ \\
\hline 2011 & 0,0012 & 0,0057 & 0,00015 & 0,0019 & 0,0247 & 0,0147 & 0,00006 & 0,0020 & 0,0000 & 0,0201 & 0,0706 \\
\hline 201 & . & 0,0069 & 0,00007 & 0,0018 & 7 & 0,0122 & 0,00007 & 0,0018 & 0,0000 & 0,0143 & 0,0701 \\
\hline 2013 & 0,0010 & 0,0085 & 0,00014 & 0,0018 & 0,0414 & 0,0089 & 0,00009 & 0,0016 & 0,0000 & 0,0114 & 0,0747 \\
\hline 2014 & 0,00 & 0,0094 & 0,00011 & 0,0017 & 0,0474 & 0,0068 & 0,00010 & 0,0008 & 0,0218 & 0,0203 & 0,1093 \\
\hline 2015 & 0,0008 & 0,0105 & 0,00005 & 0,0016 & 0,0538 & 0,0045 & 0,00011 & 0,0012 & 0,0212 & 0,0228 & 0,1167 \\
\hline 2016 & 0,0008 & 0,0113 & 0,00005 & 0,0016 & 0,0586 & 0,0076 & 0,00012 & 0,0011 & 0,0252 & 0,0293 & 0,1356 \\
\hline GR $(\%)$ & $-8,21$ & 14,45 & $-19,22$ & $-3,46$ & 18,80 & $-12,32$ & 13,77 & $-11,74$ & 7,64 & 7,90 & 13,96 \\
\hline
\end{tabular}

Sumber: Analisis Data (2017)

\section{Analisa dan Evaluasi Upaya Pajak (Tax Effort).}

Agar dapat dilakukan analisis terhadap upaya pajak yang telah dilakukan oleh Pemerintah Kabupaten Tanjung Jabung Barat melalui Badan Pengelola Pajak dan Retribusi
Daerah Kabupaten Tanjung Jabung Barat dan Organisasi Perangkat Daerah (OPD) lain yang terkait dengan pajak dan retribusi daerah. Penetapan Standar Kinerja pada upaya pajak (tax effort) dengan menggunakan skala ordinal sebagai berikut :

Tabel 9. Standar Kinerja Upaya Pajak (Tax Effort)

\begin{tabular}{ccc}
\hline No & Jumlah Nilai & Kategori \\
\hline 1 & Lebih dari $85 \%$ & Sangat Baik \\
2 & $70 \%$ s.d kurang dari $85 \%$ & Baik \\
3 & $55 \%$ s.d kurang dari $70 \%$ & Cukup \\
4 & Kurang dari $55 \%$ & Kurang \\
\hline
\end{tabular}

Capaian kinerja dihasilkan dari pengukuran kinerja melalui upaya pajak yang telah dilakukan. Pengukuran kinerja tersebut tidak dimaksudkan untuk memberikan penghargaan maupun hukuman kepada pelaksana kegiatan, namun digunakan untuk menilai tingkat efektivitas hasil kerja yang dilaksanakan oleh satuan kerja guna meningkatkan kinerja pajak daerah melalui peningkatan upaya pajak lebih baik.

Selanjutnya analisa dan evaluasi kinerja diperlukan untuk mengidentifikasi faktor-faktor penyebab keberhasilan dan ketidakberhasilan kinerja yang pada akhirnya dapat disimpulkan adanya masalah kinerja sebagai bahan pengambilan keputusan manajemen untuk meningkatkan kinerja melalui alokasi, distribusi dan regulasi.

Adapun upaya pajak (tax effort) terhadap pajak daerah yang hendak dianalisa dan dievaluasi dapat diuraikan pada penjelasan sebagai berikut :

\section{Upaya Pajak (Tax Effort) Pajak Daerah}

Upaya pajak (tax effort) terhadap penerimaan pajak daerah yang telah dilakukan Badan Pengelola Pajak dan Retribusi Daerah Kabupaten Tanjung Jabung Barat kurun waktu 2011-2016 tergolong sangat baik, namun untuk tahun 2012, 2015 dan 2016 nilai tax effortnya dibawah 100 persen. Hal ini disebabkan krisis global tahun 2015 yang menerpa ekonomi dunia berdampak terhadap ekonomi Kabupaten Tanjung Jabung Barat, dimana harga komoditi sektor pertanian terutama sektor perkebunan turun drastis seperti harga sawit turun dari $\mathrm{Rp}$ 1.850 per $\mathrm{kg}$ menjadi hanya $\mathrm{Rp} 400$ per $\mathrm{kg}$, demikian juga harga karet turun dari Rp 25.000 per kg menjadi hanya $\mathrm{Rp} 3.000$ per kg. Kondisi ini berpengaruh pada pendapatan petani yang merosot turun, sehingga berdampak pada daya beli petani terutama untuk kebutuhan sekunder dan kebutuhan tersier.

\section{Pengaruh Pajak Daerah Terhadap Pendapatan Asli Daerah}

Pada tabel berikut dapat dilihat pengaruh 
masing-masing Pajak Daerah Terhadap Pendapatan Asli Daerah Kabupaten Tanjung Jabung Barat tahun 2011-2016. Berdasarkan persamaan regresi sederhana, pajak daerah total signifikan terhadap PAD dengan pengaruhnya sebesar 79,2 persen. Selanjutnya untuk masing-masing pajak terdapat empat jenis pajak yang signifikan yaitu pajak restoran, pajak penerangan jalan, pajak air bawah tanah dan pajak PBB-P2. Pajak restoran R square $\left(R^{2}\right)$ sebesar 74,0 persen, pajak penerangan jalan $R$ square $\left(R^{2}\right)$ sebesar 67,4 persen, pajak air bawah tanah (ABT) dan pajak PBB-P2 $\mathrm{R}$ square $\left(\mathrm{R}^{2}\right)$ sebesar 69,0 persen.

Tabel 10. Pengaruh Masing-masing Pajak Daerah terhadap Pendapatan Asli Daerah (PAD) Kabupaten Tanjung Jabung Barat Tahun 2011-2016

\begin{tabular}{|c|c|c|c|c|c|}
\hline Pajak & Persamaan Regresi PAD $=a+b T$ & $\mathbf{R}^{2}$ & F hitung & Sig. & Share Thdp PAD (\%) \\
\hline Pajak Daerah & $\begin{array}{c}33968588928,9+2,089 \mathrm{~T} \\
(3,610) \quad(3,901)\end{array}$ & 0,792 & 15,219 & 0,018 & 22,839 \\
\hline Hotel & $\begin{array}{c}274584540173,8+259,53 \mathrm{~T} \\
(1,056)\end{array}$ & 0,388 & 2,533 & 0,187 & 0,233 \\
\hline Restoran & $\begin{array}{l}33203415383,07+23,343 \mathrm{~T} \\
(3,009) \quad(3,373)\end{array}$ & 0,740 & 11,374 & 0,028 & 2,102 \\
\hline Hiburan & $\begin{array}{l}68726248686,7-61,353 \mathrm{~T} \\
(6,798) \quad(-0,207)\end{array}$ & 0,011 & 0,043 & 0,846 & 0,031 \\
\hline Reklame & $\begin{array}{l}621061463,58+241,11 \mathrm{~T} \\
(0,016) \quad(1,737)\end{array}$ & 0,430 & 3,017 & 0,157 & 0,425 \\
\hline Penerangan Jalan & $\begin{array}{lr}38960233150,2 & +3,910 \mathrm{~T} \\
3,535) & (2,875)\end{array}$ & 0,674 & 8,266 & 0,045 & 10,267 \\
\hline Mineral & $\begin{array}{l}90108668372,46-18,542 \mathrm{~T} \\
(5,671) \quad(-1,561)\end{array}$ & 0,379 & 2,437 & 0,193 & 2,064 \\
\hline ABT & $\begin{array}{l}36069418600,17+2066,271 \mathrm{~T} \\
(3,060)\end{array}$ & 0,680 & 8,486 & 0,044 & 0,022 \\
\hline SBW & $\begin{array}{l}88205200679,79-102,462 \mathrm{~T} \\
(4,633) \quad(-1,173)\end{array}$ & 0,256 & 1,376 & 0,306 & 0,339 \\
\hline PBB-P2 & $\begin{array}{l}53674189148,75+6,145 \mathrm{~T} \\
(8,163) \quad(2,981)\end{array}$ & 0,690 & 8,888 & 0,041 & 2,814 \\
\hline ВРНTВ & $\begin{array}{l}54419554074,46+4,170 \mathrm{~T} \\
(4,806)\end{array}$ & 0,343 & 2,087 & 0,222 & 4,543 \\
\hline
\end{tabular}

Sumber: Data Diolah (2017)

Ket. ( ) = Nilai thitung

$\mathrm{T}=$ Pajak Daerah (Hotel, Restoran, Hiburan, Reklame, Penerangan Jalan, Mineral, Air bawah tanah, Sarang burung walet, PBB-P2, BPHTB).

Dari gambaran pada tabel diatas menunjukkan bahwa total pajak daerah secara statistik dapat menjelaskan perubahan PAD Kabupaten Tanjung Jabung Barat sebesar 79,2 persen dan signifikan. Dengan demikian pengaruh pajak daerah terhadap $\mathrm{PAD}$ sangat besar dan berpengaruh, sehingga diperlukan strategi yang baik untuk mendongkrak peningkatan PAD yang padagilirannya dapat meningkatkan APBD Kabupaten Tanjung Jabung Barat pada masa yang akan datang.
Estimasi Potensi Pajak Daerah Kabupaten Tanjung Jabung Barat Tahun 2017-2022

Untuk menentukan estimasi potensi pajak daerah, maka model yang dilakukan dengan persamaan simultan, potensial tax base, pertumbuhan ekonomi, PDRB Per Kapita, Pertumbuhan Objek Pajak serta Tax Capacity pada tahun sebelumnya. Berdasarkan data tersebut, maka hasil estimasi memberikan gambaran potensi dan target pajak daerah pada lima tahun mendatang. 
Tabel 11. Estimasi Potensi dan Target Pajak Daerah Kabupaten Tanjung Jabung Barat Tahun 2017-2022.

\begin{tabular}{lrrr}
\hline \multicolumn{1}{c}{ Tahun } & Potensi $(\mathbf{R p )}$ & Target $(\mathbf{R p )}$ & \multicolumn{1}{c}{ Rasio Target dgn Potensi } \\
\hline 2017 & 34.334 .311 .186 & 29.184 .164 .508 & 0,85 \\
2018 & 37.363 .309 .319 & 31.758 .812 .921 & 0,85 \\
2019 & 41.805 .725 .739 & 37.625 .153 .165 & 0,90 \\
2020 & 46.287 .543 .913 & 41.658 .789 .521 & 0,90 \\
2021 & 50.743 .376 .193 & 45.669 .038 .574 & 0,90 \\
2022 & 54.663 .462 .918 & 49.197 .116 .626 & 0,90 \\
GR $(\%)$ & 9,75 & 11,01 & \\
\hline
\end{tabular}

Sumber: Data diolah , 2017

Perkembangan yang terjadi pada sektorsektor penerimaan Pajak Daerah yang ada membawa pengaruh terhadap peningkatan atau perkembangan penerimaan Pajak Daerah secara total di Kabupaten Tanjung jabung Barat. Jika dilihat dari besarnya target dan potensi pajak daerah tiap tahunnya terlihat bahwa potensi penerimaan pajak daerah Kabupaten Tanjung Jabung Barat cukup tinggi diatas target yang ditetapkan. Ini berarti bahwa penerimaan daerah dari sektor pajak daerah sangat potensial sehingga sangat memungkinkan bagi pemerintah daerah untuk menghasilkan penerimaan pajak daerah melebihi target yang telah ditetapkan. Jika dilihat dari rasio target dengan potensinya dari tahun 2017 - 2022, adapun rasio target dan potensi yang tertinggi terjadi pada tahun 2019 yaitu sebesar 0,90 sedangkan rasio target dan potensi yang terendah terjadi pada tahun 20172018 dengan rasio sebesar 0,85 .

\section{SIMPULAN}

1. Dari hasil analisis klasifikasi pajak daerah beradasarkan analisis overlay, pajak daerah yang masuk kelompok prima adalah pajak penerangan jalan, BPHTB, PBB P2, Restoran, Reklame dan Hotel. Pajak daerah yang masuk kelompok berkembang adalah Air Bawah Tanah, kemudian Pajak Daerah yang masuk kelompok potesial adalah Pajak Mineral dan Sarang Burung Walet, sedangkan kelompok terbelakang adalah pajak hiburan.

2. Berdasarkan analisis Diagram Cartesius dengan Taxable Capacity dan Tax Effort, pajak penerangan jalan, pajak PBB P2 dan Pajak Daerah masuk kelompok High Effort dan High Capacity, Pajak BPHTB masuk kelompok Low Effort dan High Capacity, pajak hotel, restoran, reklame, air bawah tanah dan hiburan masuk kelompok high effort dan low capacity, sedangkan pajak sarang burung walet dan pajak mineral masuk kelompok low effort dan low capacity.

3. Berdasarkan analisis Diagram Cartesius dengan Taxable Capacity dan Tax Growth, Kelompok yang masuk High Capacity dan High Growth adalah Pajak Penerangan Jalan dan Pajak daerah, Kelompok High Capacity dan Low Growth adalah Pajak BPHTB dan PBB P2, Kelompok Low Capacity dan High Growth adalah pajak Restoran dan Air Bawah Tanah, Kelompok Low Capacity dan Low Growth adalah pajak hotel, reklame, mineral dan sarang burung walet.

4. Berdasarkan analisis Diagram Cartesius, bahwa kondisi pajak daerah di Kabupaten Tanjung Jabung Barat terutama pajak penerangan jalan terdapat kekuatan baik dari sisi kapasitas potensi pajak, usahanya dan pertumbuhannya relatif sangat baik, namun untuk pajak Pajak PBB P2 pertumbuhannya dibawah rata-rata, hal ini terjadi karena pajak PBB P2 ini baru digarap pada tahun 2014. Untuk Pajak Restoran pertumbuhannya juga dibawah rata-rata, namun potensinya sangat tingggi, karena pajak ini sangat berkorelasi positif dengan belanja daerah. Selanjutnya untuk pajak lainnya dari tiga kategori variabel yang diukur, hanya 1 yang diatas rata-rata, sedangkan untuk pajak mineral, sarang burung walet dan hiburan semua indikator kategori seperti kapasitas, effort dan pertumbuhan termasuk kategori rendah.

5. Dengan perhitungan regresi sederhana, pajak daerah total signifikan terhadap PAD dengan pengaruhnya sebesar 79,2 persen. Selanjutnya untuk masing-masing pajak terdapat empat jenis pajak yang signifikan yaitu pajak restoran, pajak penerangan jalan, pajak air bawah tanah dan pajak PBB-P2. Pajak restoran $\mathrm{R}$ square $\left(\mathrm{R}^{2}\right)$ sebesar 74,0 persen, pajak penerangan jalan $R$ square $\left(R^{2}\right)$ sebesar 67,4 persen, pajak air bawah tanah (ABT) dan pajak PBB-P2 R square $\left(\mathrm{R}^{2}\right)$ sebesar 69,0 persen.. 


\section{DAFTAR PUSTAKA}

Atep Adya Brata, Pelayanan Prima Untuk Meningkatkan Penerimaan Daerah. PT. Elek Media, Jakarta 2004.

Bahl (1971), makalah "A Regression Approach to Tax Effort and Tax Ratio Analysis"

Devas, Nick. Brian Binder. Anne Booth. Kenneth Davey.Roy Kelly, 1989. Keuangan Pemerintah Daerah di Indonesia. Penerjemah Masri Maris. Jakarta: UI Press.

E. Koswara Kertapraja, Pemerintah Daerah. Konfigurasi Politik, Desentralisasi dan Otonomi Daerah Dulu, Kini dan Tantangan Globalisasi. Penerbit Inner Kerjasama dengan Universitas Setyagama, Jakarta, 2012.

Insukindro, Mardiasmo, Widayat, W., Jaya, W.K., Purwanto, B.M., Halim, A., Suprianto, J., Purnomo, A.B., 1994, Peranan dan Pengelolaan Keuangan Daerah Dalam Usaha Peningkatan PAD, Buku I, KKD FE UGM, Yogyakarta.

Jaya, W.K., 1996, "Analisis Keuangan Daerah; Pendekatan Makro", Model Program PMSES, Kerjasama Ditjrn PUOD Depdagri dengan Pusat Penelitian dan Pengkajian Ekonomi dan Bisnis, UGM, Yogyakarta.

Kenny, D.A. (1979). Correlation and Causality. New York: John Willey \& Sons, Inc.

Kerlinger, FN et.al (1973). Multiple Regression in Behavioral Research, New York: Holt Rinehart and Winston Inc.

Lains, Alfian, 1995. "Pendapatan Daerah Dalam Ekonomi Orde Baru" , Prisma No. 4, 40-57.

Living Stone, Ian and Chartlon, Roger, 1998, "Raising Local Authority District Renenues Through Direct Taxation in A Law-Income Developing Country: Evaluation Uganda's GPT", Public Administration and Development, Vol 18, No.5, December, 499-517 